\title{
Inmigración japonesa hacia Colombia: primeros pasos de una larga marcha
}

\author{
Hansel Mera' \\ Universidad del Valle, Cali, Colombia \\ Red de Estudios Históricos Urbanos del Suroccidente de Colombia (REHUSO), Cali, Colombia \\ hansel.mera@correounivalle.edu.co \\ https://orcid.org/0000-0003-4927-0581
}

San Miguel, I. (2018). En pos de El Dorado: inmigración japonesa a Colombia.

Fondo de Cultura Económica.

\begin{abstract}
Todo el que ha viajado ha experimentado el placer de la llegada; pero pocos tendrán idea de la intensidad de este gusto después de una arriesgada travesía al llegar á un país desconocido. En esta ocasión yo olvidé todos mis sufrimientos al contemplar el hermoso panorama que tenía á la vista. Á la derecha de levantaba el majestuoso "Fudjiama" gran montaña de 3800 metros de altura, coronada de nieve. Los rayos del sol naciente, al reflejar sobre su blanca cúspide, le daban el aspecto de una pirámide sembrada de este curioso pueblo.
\end{abstract}

(Tanco, 1888, s.p.).

El epígrafe de Nicolás Tanco Armero, uno de tantos viajeros decimonónicos insertos en las coordenadas narrativas que implicaba el arte de escribir sobre esa otredad distante, es la excusa perfecta para que replanteemos no solo el rumbo de un análisis y diálogo, sino mejor, la propia forma en que hemos construido una narrativa sobre lo nacional, lo regional y lo local. Una cuestión mucho más propicia cuando pensamos en hombres y mujeres que llegaron a lo largo de este siglo XX y que, en últimas, da cuenta del valor del presente libro de la antropóloga Inés San Miguel, titulado En Pos de El Dorado, Inmigración Japonesa a Colombia (primera edición en castellano de un texto publicado en inglés, en 2002).

Digamos de antemano que los estudios sobre migraciones no son uno de los asuntos preferidos de la historiografía nacional, aunque sí suelen ser recurrentes en el campo de la sociología, a pesar de que ella se ciña a marcos temporales mucho más recientes ${ }^{2}$. En general, este libro aborda la llegada

$1 \quad$ Magíster en Sociología.

2 Un reciente ejemplo historiográfico: ver Alberto Donadío (2014). 
a Colombia, entre 1929 y 1935, de tres grupos de familias que venían con patrocinio del gobierno japonés, un total de 159 personas, de las cuales la mitad era menor de 14 años y, en breve, retoma la llegada de 63 más, por otras vías. Una pequeña gota en el mar de la migración hacia Latinoamérica, al menos entre 1897 y 1942, cuando llegaron 244.946 japoneses. En su mayoría, concentrados en Brasil, México, Perú y Argentina.

La clave interpretativa que propone Inés San Miguel Camargo se centra menos en el impacto económico de la inmigración, y más en el análisis de las transformaciones que sufrieron esos migrantes al reubicarse en un entorno nuevo, sufriendo desafíos relacionados con la incompatibilidad cultural; la ruptura con los hogares; la implementación de estrategias de sobrevivencia, como la adopción de valores; y las nuevas formas con las cuales dotaron su vida de sentido. En concreto, el papel de las transformaciones en el plano de la subjetividad y de la cultura de estos emigrantes es un muy acertado punto de vista de la autora. A lo largo de los cinco capítulos estructurados sobre la base de metodologías documentales y entrevistas, se destaca la consulta de archivos diplomáticos, el seguimiento a repertorios hemerográficos nacionales y la construcción de un rapport con los descendientes de estos emigrantes, para acceder a los subterfugios de la memoria, y a álbumes familiares.

El primer capítulo es una introducción extensa al texto, en la que se contextualiza el problema de la migración hacia Latinoamérica, durante la segunda mitad del XIX, y hacia Colombia, un país no tan atractivo para aventurarse, sobre todo por la abierta oposición que manifiesta el programa Regeneracionista, desde finales de siglo XIX, hacia ese tipo de avanzadas. Empero, hay dos elementos que se entrecruzan para dar origen a la cuestión. Primero, el Acuerdo de Caballeros entre Estados Unidos y Japón (1907-1908), en medio de una oleada contra la migración japonesa, obligó a que el gobierno de la isla mirara hacia Latinoamérica. En segundo lugar, la firma del tratado de Amistad, Comercio y Navegación (1908), entre Colombia y Japón, que concedía formalmente a los japoneses el derecho para el arribo y asentamiento, así como el establecimiento de cónsules honorarios en ambos países, en cuyo marco arribó Tamahiro Kawaguchi, jardinero cuyas destrezas se exhibieron en la Feria Industrial de 1910.

De resultas, entre 1915 y 1930 arribó un pequeño contingente de jóvenes solteros provenientes del Caribe para establecerse en Barranquilla y Usiacurí, emulando la marcha de María Abdala, hacia ese crisol cultural en que libaneses y franceses hicieron de las suyas. Posteriormente, entre 1929 y 1935 una comunidad de japoneses se estableció en las proximidades de Corinto y Caloto. Ambos grupos, según San Miguel, "en promedio, permanecieron unos veinte años en los sitios originales de asentamiento elegidos por la empresa de inmigración. Posteriormente, el grueso de ellos se trasladó al norte del Valle del Cauca, donde la tierra agrícola era mucho más fértil" (p. 30). Hasta aquí, se puede constatar un meditado ejercicio introductorio en el que se contextualiza y delimita una población base de trabajo. La autora nos recuerda: "durante la década de 1920, algunos emigrantes japoneses independientes ya se habían establecido en las ciudades de Cali y Palmira" (p. 2). Evidentemente, seguir el paso de este tipo de emigrantes es mucho más complejo y no es el interés de la autora.

En su segundo capítulo, el libro analiza las leyes de inmigración colombianas y sus contextos políticos e intelectuales circundantes, destacando la fuerza de inercia del discurso racista a favor de la migración blanca y en desmedro de la "raza amarilla". Elemento presente desde finales del siglo XIX hasta la Guerra del Pacífico. Por ende, el periodo se caracterizó por la ambivalencia gubernamental expresa en leyes a favor de la inmigración, contradichas por la creencia en el potencial negativo de la raza amarilla y por la falta de recursos para ofrecer incentivos económicos, limitando los flujos de emigrantes japoneses. Así, por ejemplo: "cuando el cónsul en Kobe, José Macías (1923-1926), recibió una solicitud japonesa en la que se expresaba la intención de llevar a Colombia un número considerable de japoneses para trabajar en la Costa Pacífica, la ignoró y no la tramitó" (p. 47). Esa negativa impidió la llegada de al menos 10.000 japoneses para trabajar en la explotación forestal del Bajo Atrato. 
Cabe destacar la llegada, en noviembre de 1927, de Takemaro Kabayoshi, designado de Industria y Comercio, solicitando baldíos en el Valle del Cauca. Símbolo de un omnipresente interés que se materializó en 1935, cuando la compañía Overseas Development compró 128 hectáreas (ha) para familias japonesas, que llegaron a pesar de la fiera oposición de la prensa y de los estudiantes de la Universidad Nacional de Colombia. Renglón aparte merece el fallido contrato firmado el 2 de octubre de 1928, entre Ken-ich Tomita y José Antonio Montalvo, mediante el cual se esperaba disponer de 10.000 ha de baldíos, en los Llanos Orientales, para 2.000 colonos japoneses, en su afán por constituir una industria arrocera y ganadera. No obstante, dos factores impidieron que todo esto se llevara a cabo: la obligación de conversión al catolicismo y la oposición de la Academia Nacional de Medicina, institución que se caracterizó por su argumentación biologicista sobre la inferioridad racial amarilla. ${ }^{3}$ Igual suerte tuvo, en 1937, la firma japonesa Nagao y Compañía de Tokio, al intentar hacerse de concesiones para una planta bananera cerca de Bahía Solano.

Por demás, este capítulo tiene el mérito de encontrar tempranos hechos indisociables de la avanzada geopolítica estadounidense en América del Sur, yendo más allá del cómodo sitial del nacionalismo metodológico. La autora apunta que, desde 1903, hubo intereses para promover la migración japonesa en el Golfo del Darién y así evitar un nuevo descalabro territorial tras la pérdida de Panamá, destacando, para 1908, el papel directriz de Rafael Reyes en esa iniciativa y su propuesta en 1920 de viajar a la isla para encabezar el esfuerzo diplomático. Anotemos que, quizá, haber explorado un poco más el panorama de la casas comerciales en Panamá (muchas, propiedad de estadounidenses), pudo haber brindado algunos elementos contextuales extra. No obstante, sí es notable la mención de la tentativa de reubicación en el nordeste de Cartagena de alrededor de 25.000 japoneses residentes en Estados Unidos. Mismo país que finalmente vio en ello una amenaza, por su cercanía con

3 Los debates de época: ver Castro-Gómez (2007).
Panamá, y porque la activación económica de ese sector, inevitablemente, fortalecería lazos diplomáticos y comerciales entre Colombia y Japón.

El tercer capítulo aúna geografías y experiencias de manera muy bien lograda. En efecto, para la autora, las políticas de emigración japonesas son una consecuencia de distintos factores. Entre estos, el proceso de apertura al mundo que vivió el país desde mediados del siglo XIX, en virtud de las reformas proclamadas por el emperador Mutsuhito: el abrazo de la ciencia, la tecnología y la cultura occidental. La serie de búsquedas de las potencias occidentales por hacerse de mano de obra japonesa y la paulatina legalización y formalización de la emigración japonesa, mediante la ordenanza Imperial 42, de 1894. Es por ello que se constituyeron, en Japón, compañías de emigración, cuyos soportes burocráticos orientaban a los migrantes y compraban tierras en el extranjero, estando encargadas de brindar procesos de asistencia.

Ahora bien, con el final de la primera guerra mundial y las sanciones impuestas por el gobierno británico, Japón se vio obligado a expandir actividades comerciales en busca de materias primas para su incipiente industria. Por lo cual, las misiones comerciales y de emigración cobraron mayores bríos, hasta cristalizar, hacia los años veinte, mediante la subvención japonesa, los programas de agricultura en Brasil, Paraguay y en Colombia. En adelante, una historia cuasi transcultural entre Japón y Colombia se encarnaría en el Jagual, un asentamiento agrícola en las cercanías de Corinto. El detenido recuento que la autora realiza sobre las compañías le permite precisar que este proceso fue organizado, supuso un dialecto compartido, una misma procedencia local y, por ende, fuertes mecanismos de cohesión social.

Uno de los puntos más interesantes tiene que ver con la reconstrucción del papel articulador de Yuzo Takeshima. Según cuenta San Miguel, en 1926, la compañía Overseas Development Company mandó dos de sus 
empleados a Colombia. Entre ellos, a Yuzo Takeshima, en virtud de su precedente labor en el Brasil con los emigrantes japoneses. 4 Takeshima, junto al experto en agricultura Tokuhisa Makisima y el embajador en Panamá, Takahiko Wakaboyoshi, iniciaron la exploración de los territorios colombianos (del 21 de julio al 18 de septiembre de 1926), visitando el Valle del Magdalena, Medellín, Santa Marta, Bogotá y el Valle del Cauca. Este es un hecho muy relevante, sobre todo cuando la historiografía regional y local solo tiende a destacar el papel de la Misión Chardon (1929). Lo cierto es que un segundo informe, esta vez solo a cargo de Takeshima, en el que se destacan las virtudes del Valle del Cauca, resultó coyuntural, pues entre 1929 y 1930 se enviaron los dos primeros grupos desde Japón, mientras Takeshima consumaba su labor, adquiriendo 128 ha en Corinto. 96 para el programa y 32 para emprendimiento personal. Entonces:

\begin{abstract}
Cada familia recibió alrededor de siete hectáreas luego de la asignación de tierras comunales para la administración y para una granja en la que se experimentaría con diferentes cultivos. Seis años después, Takeshima vendió sus tierras a la Overseas Cooperative Society of Fukuaka y estas 32 hectáreas, a las que se sumaron otras 70 que él negoció en la zona contigua a la colonia, sirvieron para recibir al tercer grupo de emigrantes provenientes de Fukuaka (p. 89)
\end{abstract}

Antes de avanzar, convengamos en que Yuzo Takeshima se convirtió en un hombre-marca bastante presente en la prensa de la Cali de los años treinta, punto que San Miguel descuida. De hecho, existen múltiples muestras de publicidad comercial y reportes gráficos que dan cuenta de la recurrencia de Takeshima, tanto en la vida política, comercial y cotidiana de esa Cali (véase Figura 1). Venideros

4 Aquí se ancla la leyenda según la cual fue Takeshima quien tradujo y publicó apartes de María, una lectura que, según el decir común, inspiró a cientos de japoneses para que buscaran el paradisiaco Valle del Cauca. La autora recuerda que, al menos desde 1910, otros informes habían recomendado una zona aledaña a Santander de Quilichao, a pesar de que en el informe hubo una referencia a María. La bella leyenda de una novela cuyas páginas fueron puentes entre dos mundos tan distantes quizá un poco de cierto tenga, aunque resulta más importante el papel de los migrantes y sus informes. abordajes podrían explorar los repositorios del Archivo Histórico Municipal de Cali y la Cámara de Comercio. Seguido de un posible caso temprano de vinculación exitosa, al mercado local, de la mano de sus saberes en torno a la agricultura y al comercio. Serían rastros que complementarían el estudio de San Miguel sobre puntos no muy presentes en su libro, como los diálogos e inserciones con las sociedades locales circundantes, una cuestión que seguramente supuso contrapiés y conflictos, estrategias de interlocución, etc. De hecho, estudios complementarios deberían analizar las relaciones entre el grupo de japoneses por entonces residentes entre Cali y Corinto, para así contrastar algunos lineamientos ya clásicos de Pierre Bourdieu, sobre la forma como la economía moderna penetra de manera diferenciada distintas capas sociales, en virtud del tipo de actividad que las define, la intensidad y duración de su contacto con el sector moderno (Bourdieu y Abdelmalek, 2017). Ello además, permitiría entrever qué papel de intermediación intercultural pudo tener un comerciante como Takeshima y sus impactos en la rutina agrícola, en tiempos de modernización urbana.

Tomemos uno de los restantes puntos fuertes del libro de San Miguel: la descripción de la vida cotidiana los habitantes de la colonia de El Jagual. Cuasi aislados e incomunicados, los habitantes de la pequeña colonia agrícola no tenían permitido vínculos comerciales sin el visto bueno de Kiyoshi Shima, un agricultor y comerciante japonés que, al menos desde la década de 1920, residía en Palmira. Durante alrededor de tres años, la colonia fungía como una jaula de hierro en la que se respetaba un ideal de la familia patriarcal, que rechazaba la actuación individual dentro de ella. La cuestión no parece haber sido muy diferente en 1935, cuando llegó un tercer grupo, aunque esta vez con la responsabilidad de pagar por sus tierras a la misma compañía. En conjunto, hablamos de hombres y mujeres que sufrieron malaria e infecciones en la piel, sin contar con atención hospitalaria cercana; sujetos a la rutina del trabajo físico extenuante con su familia, quienes tuvieron que edificar sus propias viviendas y asegurar agua subterránea. La autora bien nos advierte que debieron ser familias en las que al menos debía haber tres adultos, tal cual estipulaba el reglamento de la compañía; compuestas por agricultores de bajos recursos y criados 

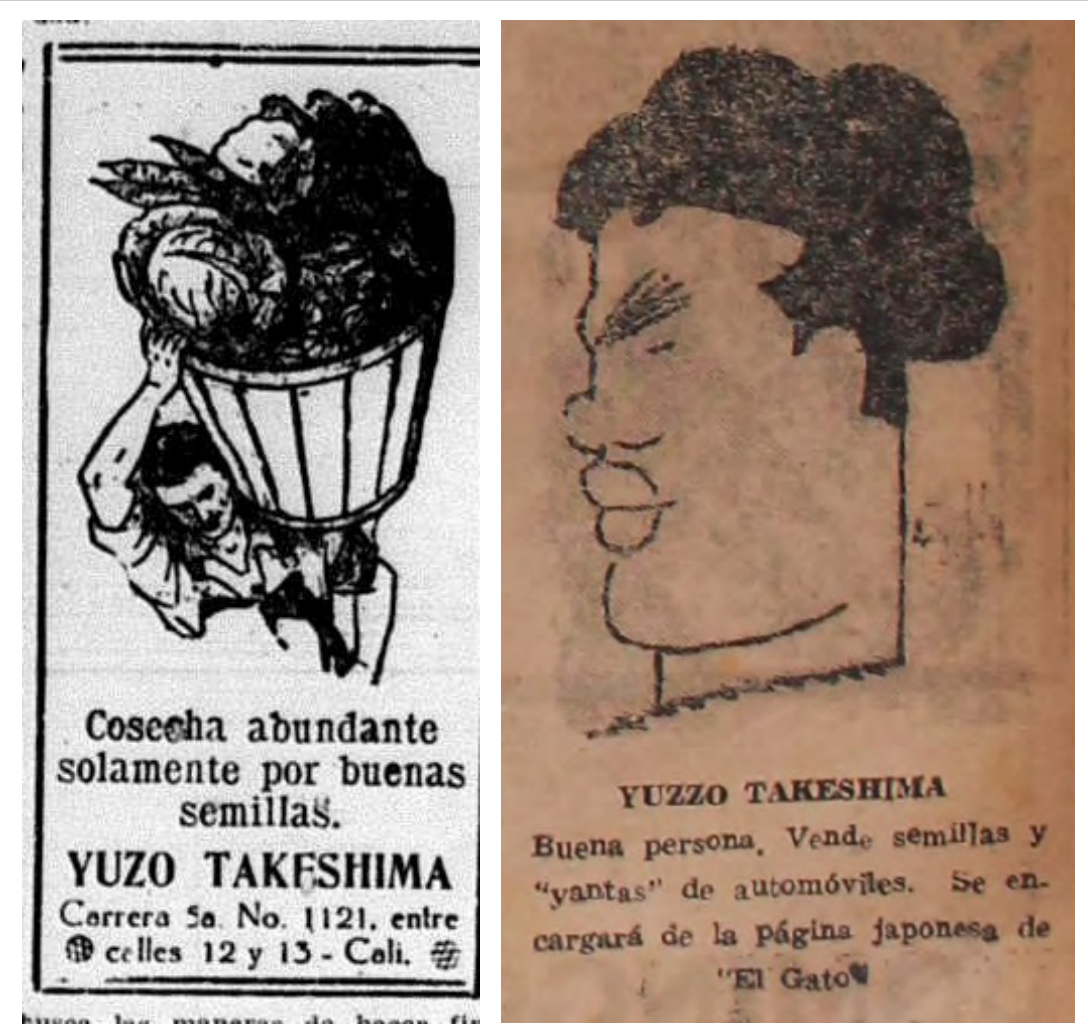

Fuente: a la izquierda Relator (1932, p. 8). A la derecha El Gato (1935, p. 3).

en el marco de estructuras familiares basadas en el primogénito como gran heredero.

El cuarto capítulo se dedica a la suerte de los inmigrantes japoneses antes de la Guerra del Pacífico. La primera tipología es la de los emigrantes urbanos, quienes carecían de vínculos con alguna compañía de emigración, estableciéndose en la costa Atlántica y en el Valle del Cauca, mientras que la segunda es la de los emigrantes rurales, familias adscritas a compañías. Se trata de una distinción útil y permite proponer que, pese a que ambos tengan rasgos generacionales e identitarios en común, incluyendo procesos educativos formales, "Al verse retados por las circunstancias, cada grupo dio forma a instituciones económicas y sociales basadas en sus raíces culturales" (p. 146).

Así, al menos desde la década de 1910, se pueden rastrear emigrantes urbanos procedentes del Perú, Panamá y del Japón, en Usiacurí y Barranquilla.
Cuyo rastro fue seguido por familiares y amigos, constituyendo un contingente de barberos, pequeños comerciantes y agricultores. En general, eran hombres de aproximadamente 30 años que lograron constituir familias numerosas con mujeres locales. A la par, hubo otro pequeño cuerpo de emigrantes que se dirigieron hacia el interior del país y Cali, siendo estos últimos cobijados por japoneses como Kaichi Tamura: propietario de una tienda de víveres y de un hotel, quien favoreció su vinculación con el Ingenio Manuelita (a pesar de que carecían de experiencia práctica en el trabajo agrícola). Dice la autora que, gracias a su buen desempeño, "después de algunos años, comenzaron a ocupar posiciones importantes en el sector agrícola (...) se creó una imagen que ayudó a la introducción de migrantes rurales japoneses en esta zona y que, en la actualidad, hace que los colombianos los relacionen con la agricultura" (p. 124). Una vez más, algunas precisiones contextuales le hubieran sido útiles a la autora para recordar la buena 
imagen de los japoneses como fuerza de trabajo para la agricultura, también se explicaba por su distancia con los procesos organizativos socialistas y comunistas que, sobre las bases de colonos y campesinos en el Valle del Cauca, adelantaron líderes como Neftalí Arce e Ignacio Torres Giraldo desde Cali y Palmira.

En todo caso, la tipología sí resulta adecuada porque da cuenta de un grupo que, en general, tenía conocimiento de la lengua castellana y que, al crear rápidamente vínculos con el ámbito urbano y comercial, interactuó con un entramado social circundante mucho más diverso, que no se agotaba en las estrechas vecindades de una identidad primaria y, aparte, edificó plataformas para los emigrantes rurales. Hubiera sido interesante saber si muchos de estos emigrantes tuvieron algún grado de participación en la agitada política nacional y local, un aspecto sobre el cual San Miguel no vuelve; aunque sí logra reconocer los espacios de socialización que fortalecieron vínculos identitarios étnicos, como las reuniones dominicales en las que la lengua japonesa, la comida y la interacción fortalecían un sistema de redes comunales, además de pequeños sistemas de ahorros y créditos entre sí.

El caso de los emigrantes rurales de El Jagual está muy bien desarrollado por la autora, quien logra delimitar lo siguiente: en 1929, había presencia de 10 familias; y en 1930 , la de 20 familias, para un total de 159 personas. A quienes se sumó, en 1935, un tercer grupo compuesto por 14 familias. Mas allá, existe una breve caracterización, según las oleadas de migración, pasando de dos a siete miembros en las siguientes experiencias, hecho que obligó a la construcción de una escuela dentro de la comunidad (subvencionada por el gobierno japonés). También favoreció la existencia, al menos por un tiempo, de un mercado matrimonial interno, evitando aquellos tropiezos sociodemográficos que Pierre Bourdieu sagazmente estudió para el Bearne. Lo que permite creer que no hubo ocasión para un baile de solteros y sí una saga de trabajo basado en la unidad familiar bajo condiciones fatigantes. Dice la autora: "Los primeros años de los emigrantes fueron dificilísimos. Trabajaban los siete días de la semana y el único día festivo era el primero de enero. Con el tiempo (...) descansarían los domingos" (p. 137).

Posteriormente, San Miguel esboza los contornos simbólicos de las unidades familiares, destacando el legado de un confucionismo que promovía una ética de devoción familiar y jerárquica ante el hombre mayor. Aspecto que seguramente se sublimó en el caso de los emigrantes urbanos, pero que en el Cajual fue mucho más fuerte, al igual que la doble carga de la mujer, que se hacía cargo de las tareas asociadas a la reproducción de la fuerza de trabajo (alimentación, cuidado) y las agrícolas. Dice la autora: "todos los miembros de una familia vivían en la misma casa, bajo las reglas del jefe de dicha familia; en otras palabras constituían un hogar en todos los derechos y obligaciones que esta unidad primera de organización social ofrecía y exigía" (p. 133). Esa labor es importante porque permite aseverar que la unidad familiar y su cohesión fue clave para la conservación de una identidad étnica.

A ciencia cierta, en este tipo de investigaciones no es fácil indagar sobre las estructuras familiares ni sobre los aspectos de la vida cotidiana. He ahí parte del mérito del libro, y que vamos a destacar de la mano de apartes documentales curiosamente no tenidos en cuenta por Inés San Miguel. Entre ellos, la Revista Estampas, una publicación en general bimensual que aunaba buena parte de la intelectualidad de los años treinta, y que, bajo el formato de la crónica periodística, recorrió las geografías menos comunes de esa Colombia, muy en la línea del programa de políticas del liberalismo5. Narra el cronista Alfredo Rodríguez Lamus -en su arribo a El Cajual por "trazados primitivos"- la vista de "casonas pajizas", construcciones sencillas y de higiene con motivos murales, en cuyos cuartos "se ven las tinajas de mosto, los sacos de cereal y los alajes de las caballerías" (Revista Estampa, 1939, p. 30.) La narrativa se vale de una foto que brinda la ilusión de recrear ese panorama, sobresaliendo un hombre en vestido, sin su traje de trabajo, y una pequeña niña que mira al fotógrafo (Figura 2). De la unidad familiar se destacan, además, algunas

5 Sobre ello: Silva (2005). 


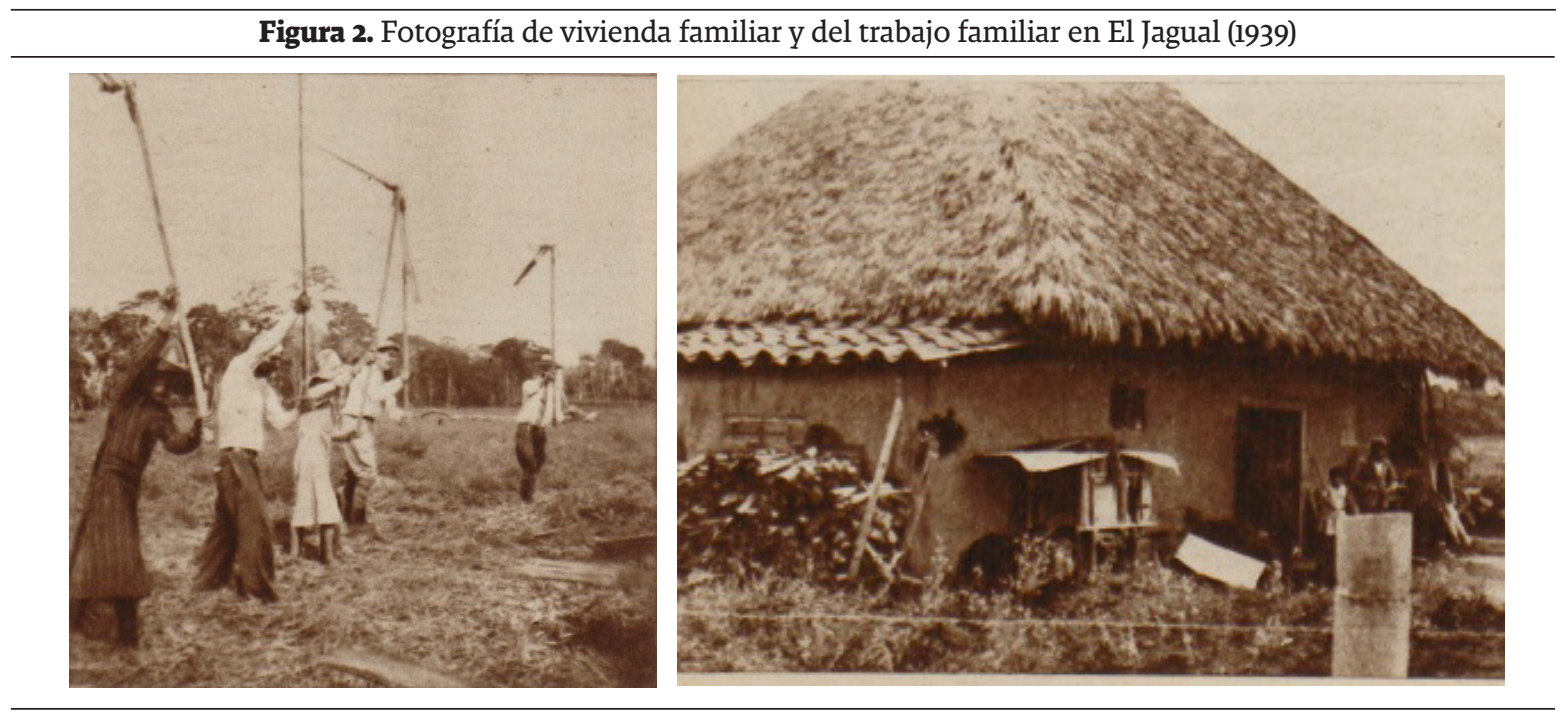

Fuente: Rodríguez-Lamus (1939, p. 30).

tejas de barro seguramente adquiridas en los pequeños mercados aledaños y pilas de leña para las cocinas y, por último, los aljibes (Figura 2).

La crónica ilustra aspectos de la vida cotidiana en el Cajual. Para 1939, refiere la existencia de al menos cuarenta familias que "únicamente pagan la sal, carne y los impuestos", una relación de autosuficiencia a no menospreciar, sobre todo porque se estaba organizando un taller de mecánica y realizaban "observaciones científicas sobre la producción" (Rodríguez-Lamus, 1939, p 30). Seguramente bajo la mirada atenta de los japoneses que habían ya trabajado en la mejora de la agroindustria local y que ya contaban con tiendas de abarrotes en Cali y Palmira. Por ende, la historia de El Jagual se vinculaba con los procesos de modernización urbanos adelantados en ciudades aledañas, todo favorecido por la mecanización de la producción que la autora constata con fotografías que muestran a los tractores en el campo. Una tecnología que seguramente coexistió con las moliendas y trilladoras para el arroz, maíz y frijol.

El último capítulo se concentra en la suerte de los emigrantes japoneses en tiempos de la Guerra del Pacífico y la posguerra. En efecto, el ataque a Pearl Harbor (7 de diciembre de 1941) justificó una serie de medidas de control y sometimiento de la población japonesa en
Colombia; tal cual, la suerte de muchos alemanes e italianos. Mediante entrevistas, prensa y archivo diplomático, la autora reconstruye una interminable serie de acusaciones de espionaje, requisas, expulsiones y confinamientos adelantados, en conjunto, por el FBI y la Policía Nacional. En un clima de paranoia, la fantasmagórica presencia de submarinos japoneses en el Pacífico vino a verse más fortalecida cuando se creyó que la colonia japonesa de El Jagual podía edificar un campo de aterrizaje fácilmente.

En ese sentido, la autora destaca que, en 1943, el servicio de inteligencia viajó hacia el Atlántico y el Valle del Cauca, pasando revista de la población japonesa. Información que se tuvo en cuenta, en 1944, "para escoger a quienes serían enviados al campo de internamiento en Fusagasugá" (p. 156). En parte, continúa, fue evidente el interés por acabar con la prosperidad comercial que habían logrado, sobre todo porque, desde El Jagual, ya se habían aventurado a dinámicas de poblamiento y producción agrícola en Candelaria, Cerrito, Florida, Miranda y Palmira. A partir de entonces, se dio un periodo de persecuciones que ocasionó en los emigrantes el desarrollo de una conciencia de su condición de minoría vulnerable.

Las palabras de la autora hallan más sustento si se revisan documentos que se encuentran en 
repositorios digitales de la Universidad de California, como la Figura 3, que sitúa a El Jagual y tierras, en teoría, en manos de propietarios alemanes (Zimmermann y Bohmer ${ }^{6}$ ). A la par, no habría que desconocer la fuerza de inercia de una intelectualidad local del Frente Popular y su constante denuncia del imperialismo japonés, tal cual las caricaturas de Alberto Arango Uribe (Figura 4). A propósito, vale recordar que la reciente guerra con el Perú supuso el establecimiento de una base aérea en Cali. Misma ciudad en que distintos periódicos y la revista Tarapaca generaron una verdadera animadversión contra el Perú, uno de los mayores focos receptores de población japonesa.

El capítulo cierra con un listado de las asociaciones desarrolladas por los emigrantes japoneses y su descendencia; quizá el mejor testimonio de su éxito, en el ámbito de la agricultura, forjado mediante el trabajo constante y rutinario. La primera cooperativa de agricultores y comerciantes a cargo de Tokuji Nishikuni, propietario de una bodega de granos en Cali, estuvo en pie entre 1930 y 1951; la Sociedad de Agricultores Japoneses (SAJA), que en 1951 buscó reunir a todos los miembros dispersos que pertenecieron a El Jagual, y que empezaron a ir más allá de sus estrechas vecindades, en el afán por hacerse de nuevas tierras cultivables en Candelaria, Cerrito, Miranda y Palmira; logrando llegar a alquilar, para 1955 , unas 13.000 ha $y$, en 1970 , ser propietarios de 1.700 ha más.

La revista continúa con otras asociaciones más efímeras como Javieres, de hombres adscritos a la religión católica; Sakura para mujeres solteras de 14 a 25 años; Fujinba para mujeres de todas las edades. La Asociación Prefectual Fukuaka, que hiló en el tiempo la procedencia de muchos de estos emigrantes, y la Asociación Colombo Japonesa, quizá la más importante de todas, cuyo repertorio de actividades culturales en torno al comercio, las clases de japonés, las muestras gastronómicas, las conferencias y las artes marciales, sigue siendo muy importante en Cali. Lo curioso es que San Miguel no se

6 Probablemente se referían a Hermann Bohmer, prestante comerciante alemán y dueño del Teatro Jorge Isaacs.

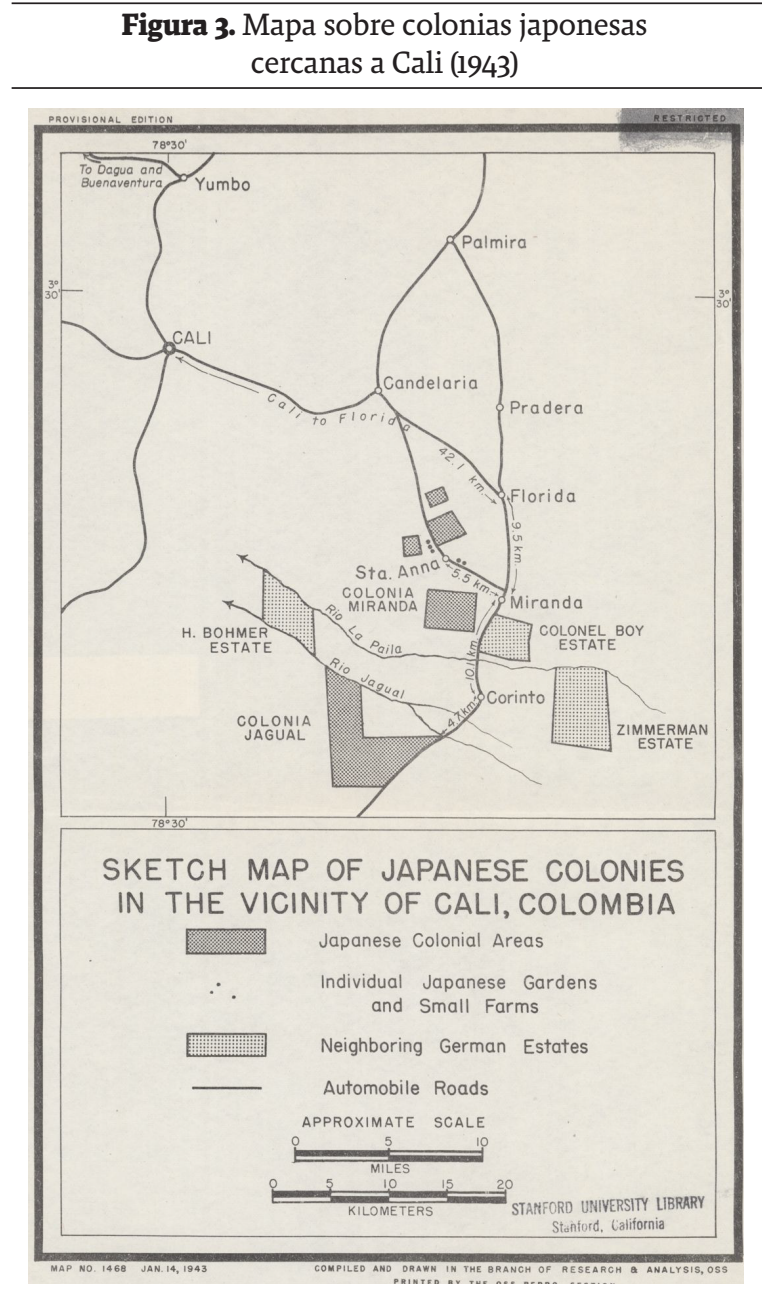

Fuente: Stanford Libraries (1943).

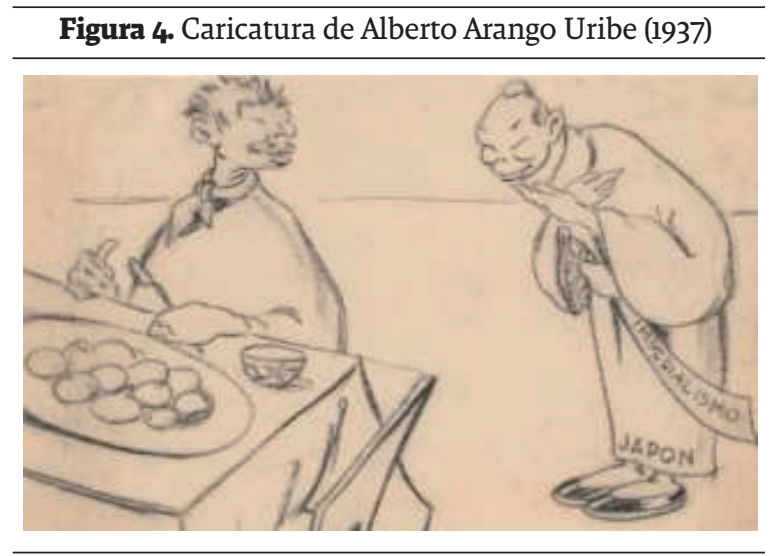

Fuente: BNC (1937). 
adentra a precisar y a entrever, en el ámbito de la religión, si hubo mayor instancia transcultural consumada, o no, en estos emigrantes japoneses y sus descendientes.

En resumen, son asociaciones diversas y complejas, cuya existencia refleja la permanencia de una identidad étnica, recreada en símbolos y expresiones en los propios hogares, mediante los cuales se da cuenta de esa adscripción desde la individualidad. Por último, la autora constata el retorno de muchos de estos descendientes de emigrantes japoneses hacia la isla, siguiendo la promesa de una mejor ventura laboral, para decir: "No es difícil encontrar similitudes y diferencias en el proceso de emigración y sus consecuencias entre los japoneses oriundos y sus descendientes. Los japoneses que primero emigraron a Colombia, o su progenie que luego lo hizo a Japón, no fueron objeto de ningún tipo de persecución política o religiosa" (p. 187). Son historias alejadas en el tiempo, de hombres y mujeres tras bonanzas, que recrean la ilusión de un movimiento pendular entre Colombia y Japón.

Vuelvo atrás, al epígrafe de Nicolás Tanco Armero, quien fue procesado por infligir castigos y tratamiento cruel a culíes transportados en condiciones de esclavitud, para trabajar en las plantaciones de azúcar en Cuba, en los ferrocarriles de Panamá y en la recolección de guano en el Perú. Entre otros casos, la historia de su infamia fue un aliciente para que el gobierno japonés siempre se asegurara de que sus súbditos emigrantes nunca sufrieran este tipo de tratamientos y, al menos en el caso de Colombia, fue así hasta el arribo de la Guerra del Pacífico. Hoy en día, la historia que presenta Inés San Miguel, sobre la inmigración japonesa a Colombia, es el mejor aliciente para repensar la suerte siempre irremediablemente compleja de la constitución de la sociedad colombiana en el siglo XX. Dice nuestra autora que, en buena medida, "lo que hace a la emigración japonesa tan singular es el grado en que fue controlada y organizada por el gobierno (...) compartir el lugar de origen, saber que las autoridades locales desempeñaban un rol no solo en cuanto a la organización de la emigración, sino también en cuanto a proporcionarles una conexión inquebrantable con la patria, fue un factor decisivo para ellos" (p. 105). El buen desarrollo del texto permite creer que tiene toda la razón. Mil grullas en 193 páginas lo corroboran.

\section{Referencias}

Biblioteca Nacional de Colombia. (1937). Caricatura de Alberto Arango Uribe. 459. Fondo Arciniegas. https://catalogoenlinea.bibliotecanacional.gov.co/client/es_ES/search/asset/3708/o

Bourdieu, P. y Abdelmalek, S. (2017). El desarraigo: violencia del capitalismo en una sociedad rural. Siglo XXI Ed.

Castro-Gómez, S. (2007). ¿Disciplinar o poblar? La intelectualidad colombiana frente a la biopolítica (1904-1934). Revista Nómadas, (26), 44-55.

Donadío, A. (2014). Los italianos de Cúcuta: pioneros del café en Colombia. Sílaba.

El Gato. (1935, 23 de marzo). Yuzo Takeshima. El Gato, p. 3.

Relator. (1932, 16 de abril). Yuzzo Takeshima. Relator, p. 8.

Rodríguez-Lamus, A. (1939, 25 de febrero). El Jagual. Una hora en la colonia japonesa. Revista Estampa, pp. 30-3l. https://catalogoenlinea.bibliotecanacional.gov.co/client/es_ES/search/asset/190894

Silva, R. (2005). República liberal, intelectuales y cultura popular. La Carreta.

Stanford Libraries. (1943). Sketch Map of Japanese Colonies in the Vicinity of Cali, Colombia. Printed by the OSS Repro. https://searchworks.stanford.edu/view/2997433

Tanco, N. (1888). Recuerdos de mis últimos viajes por Japón. Biblioteca Nacional de Colombia. 